Chapter 5

\title{
Formability Characterization of Titanium Alloy Sheets
}

\author{
F. Djavanroodi and M. Janbakhsh \\ Additional information is available at the end of the chapter \\ http://dx.doi.org/10.5772/55889
}

\section{Introduction}

Recently, different industries faced the challenge of implementation of titanium alloys in order to produce components with different formability characteristics. Titanium alloy sheets are defined as hard-to-form materials regarding to their strength and formability characteristics. Consequently, in order to soundly manufacture a part made from the mentioned alloys, novel processes such as hydroforming, rubber pad forming and viscous pressure forming instead of conventional stamping or deep drawing are applied.

In sheet metal forming industries, FE simulations are commonly used for the process/tool design. Availability of suitable mechanical properties of the sheet material is important factor for obtaining accurate FE simulations results.

\subsection{Biaxial bulge test}

The most commonly used method to investigate the flow stress curve is uniaxial tensile test in which true stress-true strain curve is expressed in uniaxial stress state. However, maximum plastic strains obtained in uniaxial loading condition is not sufficient for most sheet metal forming simulation processes which involve biaxial state of stress [1-5]. Hydraulic bulge test is a comparative test method in which biaxial stress-strain curve could be attained. In 1950, a key theoretical pillar for the hydraulic bulge test was established by Hill [6]. In his study, Hill assumed a circular profile for the deforming work piece which allowed for the introduction of a closed form expression for the thickness at the pole region [5].

The experimental bulge test method involves pumping hydraulic fluid [4, 7-10] or a viscous material as a pressure medium [2-3, 11] instead of a hydraulic fluid into the die cavity. Circular as well as elliptical dies can also be used to determine anisotropy coefficients of material in different directions with respect to rolling direction [12-15]. 


\subsection{Forming Limit Diagrams (FLD)}

As mentioned before, due to increased demand for light weight components in aerospace, automotive and marine industries, recently, titanium sheet alloys have gained ever more interests in production of structural parts. In order to better understand the cold formability of these alloys, their behavior in sheet metal forming operations must be determined both experimentally and theoretically. Sheet metal formability is often evaluated by forming limit diagram. The concept of FLD was first introduced by Keeler [16] and Goodwin [17]. Forming limit diagram provides the limiting strains a sheet metal can sustain whilst being formed. Laboratory testing has shown that the forming limit diagrams are influenced by several factors including strain hardening exponent and anisotropy coefficients [18-20], strain rate [21-23], temperature [24], grain size and microstructure [25-26], sheet thickness [27], strain path changes [28-29], and heat treatment [30].

In recent years many experimental techniques have been developed to investigate the FLDs from different aspects [31-34]. These studies were based on elimination of frictional effects resulted from toolsets and materials, the uniformity of the blank surface and mechanical properties of sheet materials deduced from the conventional tensile testing.

The available tests for the determination of FLDs include: hydraulic bulge test [35], Keeler punch stretching test [36], Marciniak test [37], Nakazima test [38], Hasek test [39] and the biaxial tensile test using cruciform specimen [40] (in short cruciform testing device). From previous studies [36-39], it is widely acknowledged that friction remains an unknown factor yet to be effectively characterized and understood. Thus, the list of available tests is greatly reduced to only two options - hydraulic bulge test and cruciform testing device. Further analysis shows that due to simplicity of equipment and specimen (i.e. less costly), hydraulic bulge test is comparatively preferred [41].

On the other hand, several researchers have proposed a number of analytical models to predict FLD. Hill's localized instability criterion [42], combined with Swift's diffused instability criterion [43] was the first analytical approach to predict FLDs. It was shown that forming limit curves are influenced by material work hardening exponent and anisotropy coefficient. $\mathrm{Xu}$ and Wienmann [44] showed that for prediction of the FLD, the shape of the used yield surface had a direct influence on the limit strains. They used the Hill'93 criterion to study the effect of material properties on the FLDs. The M-K model [45] predicts the FLD based on the assumption of an initial defect in perpendicular direction with respect to loading direction. The assumption made for this non-homogeneity factor is subjective and hence, the forming limit diagram is directly influenced by it. This method was then developed considering the material properties [46-47].

Several researchers used the ductile fracture criteria for forming limit predictions in hydroforming process [48], deep drawing process [49], bore-expanding [50] and biaxial stretching [51]. Fahrettin and Daeyong [52] and Kumar et al. [53] proposed the thickness variations and the thickness gradient criterion respectively. These criteria are limited because they require precise measurements of thickness. Bressan and Williams [54] used the method of shear instability to predict the FLDs. Consequently, experimental techniques are widely accepted 
for determination of the FLDs and for verification of the predicted FLDs resulted from analytical models.

Djavanroodi and Derogar [19] used the Hill-Swift model to predict the limit strains for titanium and aluminum sheets. They performed hydroforming deep drawing test in conjunction with a novel technique called "floating disc" to determine the FLDs experimentally. It was concluded from their work that as strain hardening exponent and anisotropic coefficients increase, the limit strains will also increase, and consequently, this allows the FLD to be shifted up.

In this chapter, different analytical approaches as well as the experimental methods are applied to obtain the uniaxial and biaxial flow stress curves for Ti-6Al-4V sheet metal alloy. The hydraulic bulge test was carried out and findings were compared with the results obtained from the uniaxial tensile test. Circular-shaped die was used. Stepwise test with gridded specimens and continuous experiments were performed. For flow stress calculations, both the dome height and pressure were measured during the bulge tests. The effects of anisotropy and strain hardening on material formability were also investigated.

On the other hand, a practical approach was implemented for experimental determination of FLD and several theoretical models for prediction of forming limit diagrams for $1.08 \mathrm{~mm}$ thick Ti-6Al-4V titanium sheet alloy subjected to linear strain paths were applied. For the experimental approach, the following test pieces have been used to obtain different regions of FLD: circle specimens to simulate biaxial stretching region of FLD (positive range of minor strain); non-grooved tensile specimens (dog-bone shaped specimens) to simulate the uniaxial strain path and two distinctive grooved tensile specimens representing the strain path ranging from uniaxial tension to plane strain region of FLD. The onset of localized necking was distinguished by investigating the strain distribution profiles near the necking region. Furthermore to predict the theoretical FLDs, Swift model with Hill93 yield criteria [55] and M-K model with Hill93 and BBC2000 yield criteria [56] were used. Predicted FLDs were compared with the experimental data to evaluate the suitability of the approaches used. Moreover, considering the extensive application of Autoform 4.4 software in sheet metal forming industries, several parts representing different strain paths were formed to evaluate the FLDs of the tested sheets numerically. The effects of process parameters as well as yield loci and material properties used in simulations were also discussed.

\section{Theoretical approaches}

\subsection{Hydroforming bulge test}

Hydroforming bulge test is one of the most commonly used balanced biaxial tests in which a circular sheet metal fully clamped between two die surfaces is drawn within a die cavity by applying hydrostatic pressure on the inner surface of the sheet. The die cavity diameter $\left(d_{d}\right.$ $\left.=2 R_{d}\right)$, the upper die fillet radius $\left(R_{f}\right)$ and initial sheet thickness $\left(t_{0}\right)$ are constant parameters of any hydroforming bulge testing. Instantaneous variables of biaxial test are: bulge pressure $(p)$, dome height $\left(h_{b}\right)$, bulge radius $\left(R_{b}\right)$ and sheet thickness at the dome apex $(t)$. The schematic view of hydroforming bulge test is shown in Fig.1. 


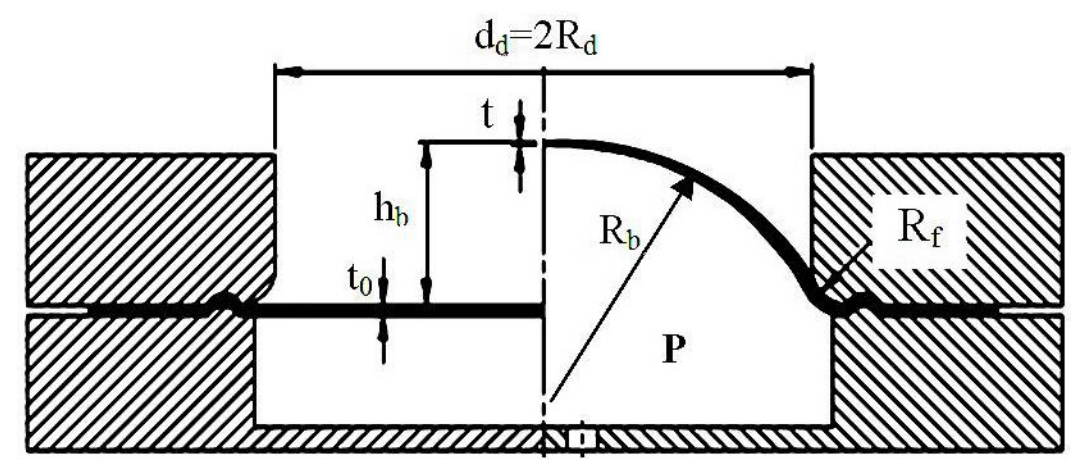

Figure 1. Scheme of the hydroforming bulge test

In order to obtain flow stress curve, first, a combination of constant and variable parameters are introduced to several equations proposed by the other researchers to calculate the instantaneous bulge radius $[6,57]$ and the sheet thickness [6, 58-59] at the dome apex. Subsequently, by making the assumption that during the bulging process the sheet metal behavior is the same as thin-walled structure and by implementing the classical membrane theory, the flow stress curves are obtained. Eqs.1 and 2 represent the theories for calculating the bulge radius proposed by Hill [6] and Panknin [57], respectively:

$$
\begin{gathered}
R_{b}=\frac{d_{d}+4 h_{b}}{8 h_{b}} \\
R_{b}=\frac{\left(R_{d}+R_{f}\right)^{2}+h_{b}^{2}-2 R_{f} h_{b}}{2 h_{b}}
\end{gathered}
$$

Eqs. 3 to 5 represents the theories for calculating the instantaneous sheet thickness at the dome apex proposed by Hill [6], Chakrabarty et al. [58] and Kruglov et al. [59], respectively. In this chapter, Eqs.1 to 5 was used in the theoretical approach.

$$
\begin{aligned}
& t=t_{0}\left(\frac{1}{1+\left(h_{b} / R_{d}\right)^{2}}\right)^{2} \\
& t=t_{0}\left(\frac{1}{1+\left(h_{b} / R_{d}\right)^{2}}\right)^{2-n}
\end{aligned}
$$




$$
t=t_{0}\left[\frac{\left(R_{d} / R_{b}\right)}{\operatorname{Sin}^{-1}\left(R_{d} / R_{b}\right)}\right]^{2}
$$

The second stage for calculating the flow stress curves for sheet material is implementing the classical membrane theory. Due to very low ratio of thickness to radius of the sheet $\left(t / R_{d}<<0.1\right)$, the stress component in perpendicular direction to sheet surface is not considered $\left(\sigma_{z}=0\right)$. By considering Tresca's yield criterion, Gutscher et al. [2], proposed an equation to evaluate the effective stress resulted from the hydroforming bulge test:

$$
\bar{\sigma}_{\text {isotropic }}=\frac{p}{2}\left(\frac{R_{b}}{t}+1\right)
$$

Principle strains at dome are: $\varepsilon_{\theta}, \varepsilon_{\phi}$ and $\varepsilon_{t}$. Assuming Von-Mises yield criterion and equality $\varepsilon_{\theta}=\varepsilon_{\phi}$, the effective strain can be calculated as:

$$
\bar{\varepsilon}_{\text {isotropic }}=\sqrt{\frac{2}{9}\left[\left(\varepsilon_{\theta}-\varepsilon_{\varphi}\right)^{2}+\left(\varepsilon_{\theta}-\varepsilon_{t}\right)^{2}+\left(\varepsilon_{\varphi}-\varepsilon_{t}\right)^{2}\right]}
$$

It is known that due to the principle of volume constancy $\left(\varepsilon_{\theta}+\varepsilon_{\phi}+\varepsilon_{t}=0\right)$, plastic deformation does not yield any volume change $[2,60]$ :

$$
\bar{\varepsilon}_{\text {isotropic }}=\varepsilon_{\theta}+\varepsilon_{\phi}=-\varepsilon_{t}=\ln \frac{t_{0}}{t}
$$

Since due to rolling conditions, sheet metal properties differ in various directions with respect to rolling direction (anisotropy), effective stress and effective strain components should be corrected for anisotropy. In Equations 6 and 8, no anisotropy correction was introduced. Consequently, assuming Hill'48 yield criterion in conjunction with plane stress assumption, Smith et al. [5], proposed equations 9 and 10 for determination of effective stress and effective strains for sheet metals considering the average normal anisotropy $(R)$, respectively.

$$
\begin{gathered}
\bar{\sigma}_{\text {anisotropic }}=\bar{\sigma}_{\text {isotropic }}\left[2-\frac{2 R}{(R+1)}\right]^{1 / 2} \\
\bar{\varepsilon}_{\text {anisotropic }}=\frac{2 \varepsilon_{\text {isotropic }}}{(2-(2 R / R+1))^{1 / 2}}
\end{gathered}
$$




\subsection{Forming Limit Diagrams}

\section{Hill93 and BBC2000 constitutive models}

In this paper Hill 93 and BBC2000 constitutive models were used to predict the FLDs. Eq.11 represents Hill'93 yield criterion [55]:

$$
\begin{gathered}
\frac{\sigma_{1}^{2}}{\sigma_{0}^{2}}-\frac{c \sigma_{1} \sigma_{2}}{\sigma_{0} \sigma_{90}}+\frac{\sigma_{2}^{2}}{\sigma_{90}^{2}}+\left[(p+q)-\frac{\left(p \sigma_{1}+q \sigma_{2}\right)}{\sigma_{b}}\right] \frac{\sigma_{1} \sigma_{2}}{\sigma_{0} \sigma_{90}}=1 \\
p=\left[\frac{2 R_{0}\left(\sigma_{b}-\sigma_{90}\right)}{\left(1+R_{0}\right) \sigma_{0}^{2}}-\frac{2 R_{90} \sigma_{b}}{\left(1+R_{90}\right) \sigma_{90}^{2}}+\frac{c}{\sigma_{0}}\right] \frac{1}{\frac{1}{\sigma_{0}}+\frac{1}{\sigma_{90}}-\frac{1}{\sigma_{b}}} \\
\frac{c}{\sigma_{0} \sigma_{90}}=\frac{1}{\sigma_{0}^{2}}+\frac{1}{\sigma_{90}^{2}}-\frac{1}{\sigma_{b}^{2}} q \\
q=\left[\frac{2 R_{90}\left(\sigma_{b}-\sigma_{0}\right)}{\left(1+R_{90}\right) \sigma_{90}^{2}}-\frac{2 R_{0} \sigma_{b}}{\left(1+R_{0}\right) \sigma_{0}^{2}}+\frac{c}{\sigma_{90}}\right] \frac{1}{\frac{1}{\sigma_{0}}+\frac{1}{\sigma_{90}}-\frac{1}{\sigma_{b}}}
\end{gathered}
$$

Where $c, p$ and $q$ are Hill' 93 coefficients and can be calculated using five mechanical parameters obtained from two uni-axial tensile tests and an equi-biaxial tension (Eq.12).

Banabic et. al [56] proposed a new yield criterion called BBC2000 for orthotropic sheet metals under plane stress conditions. The equivalent stress is defined as:

$$
\bar{\sigma}=\left[a(b \Gamma+c \Psi)^{2 k}+a(b \Gamma-c \Psi)^{2 k}+(1-a)(2 c \Psi)^{2 k}\right]^{\frac{1}{2 k}}
$$

Where $a, b, c$ and $k$ are material parameters, while $\Gamma$ and $\Psi$ are functions of the second and third invariants of a fictitious deviatoric stress tensor and can be expressed as explicit dependencies of the actual stress components:

$$
\begin{aligned}
& \Gamma=(d+e) \sigma_{11}+(e+f) \sigma_{22} \\
& \Psi=\sqrt{\left[\frac{1}{2}(d-e) \sigma_{11}+\frac{1}{2}(e-f) \sigma_{22}\right]^{2}+g^{2} \sigma_{x y}^{2}}
\end{aligned}
$$

Where $d, e, f$ and $g$ are anisotropy coefficients of material and $k$-value is set in accordance with the crystallographic structure of the material ( $k=3$ for BCC alloys and $k=4$ for FCC alloys). For the BBC2000 yield model, the detailed description can be found in [56]. 


\section{Theoretical prediction of the FLD}

The simulation of plastic instability is performed using M-K and Hill-Swift analysis. The rigid plastic material model with isotropic work hardening and the plane stress condition were assumed.

A detailed description of the theoretical M-K analysis, schematically illustrated in Fig.2, can be found in [45]. The M-K model is based on the growth of an initial defect in the form of a narrowband perpendicular to the principal axis. The initial value of the geometrical defect $\left(f_{0}\right)$ is characterized by Eq.15, where $t^{a}{ }_{0}$ and $t^{b}{ }_{0}$ are the initial thicknesses in the homogeneous and grooved region, respectively.

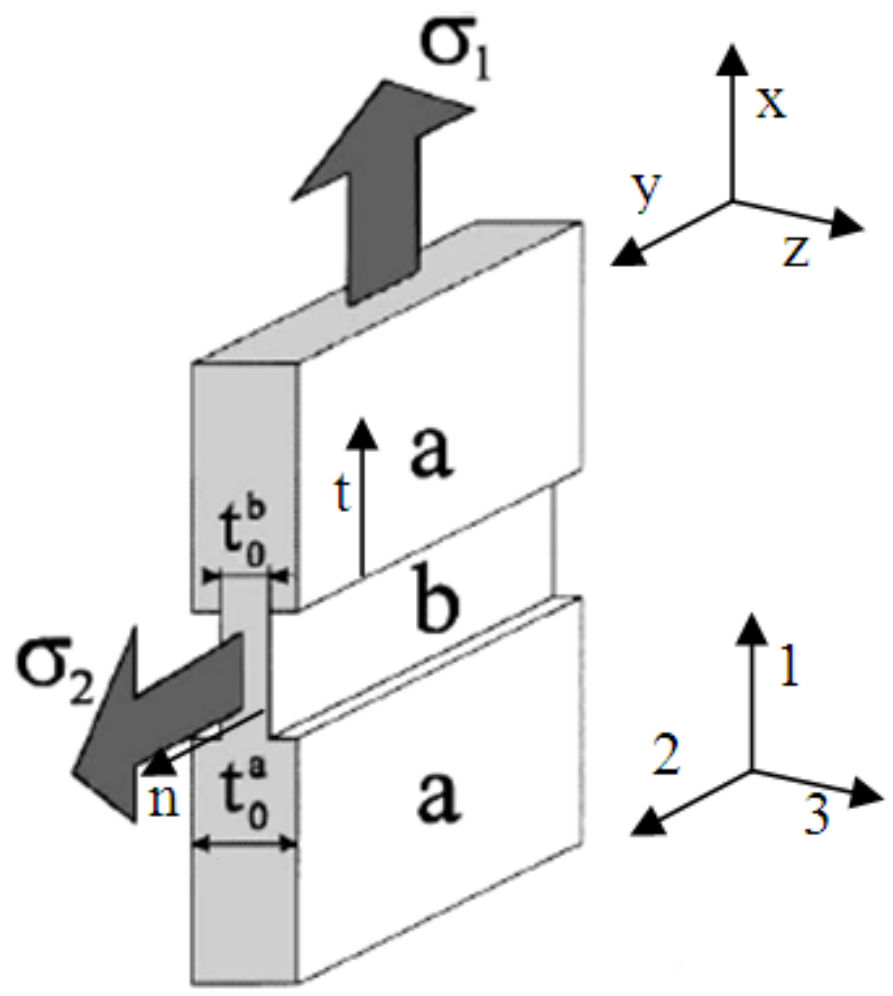

Figure 2. Schematic description of M-K model

$$
f_{0}=\frac{t_{0}^{b}}{t_{0}^{a}}
$$


The $\mathrm{x}, \mathrm{y}, \mathrm{z}$-axes correspond to rolling, transverse and normal directions of the sheet, whereas 1 and 2 represent the principal stress and strain directions in the homogeneous region. The set of axis bound to the groove is represented by $n, t, z$-axes where ' $t$ ' is the longitudinal one. The plastic flow occurs in both regions, but the evolution of strain rates is different in the two zones. When the flow localization occurs in the groove at a critical strain in homogeneous region, the limiting strain of the sheet is reached. Furthermore, the major strain is assumed to occur along the X-axis. M-K necking criterion assumes that the plastic flow localization occurs when the equivalent strain increment in imperfect region (b) reaches the value ten times greater than in homogeneous zone (a) $\left(d \varepsilon_{b}>10 d \varepsilon_{a}\right)$. When the necking criterion is reached the computation is stopped and the corresponding strains $\left(\varepsilon_{\mathrm{a}}^{\mathrm{xx}}, \varepsilon_{\mathrm{a}}^{\mathrm{yy}}\right)$ obtained at that moment in the homogeneous zone are the limit strains. For the model, equation expressing the equilibrium of the forces acting along the interface of the two regions could be expressed as follow:

$$
\sigma_{1 a} t_{a}=\sigma_{1 b} t_{b}
$$

Strains parallel to the notch are equal in both regions:

$$
d \varepsilon_{2 a}=d \varepsilon_{2 b}
$$

In addition, the model assumes that the strain ratio in zone $a$, is constant during the whole process:

$$
d \varepsilon_{2 a}=\rho d \varepsilon_{1 a}
$$

Detailed FLD calculation using BBC2000 yield criterion is presented in [61]. Swift workhardening model with strain rate sensitivity factor was used:

$$
\bar{\sigma}=K\left(\varepsilon_{0}+\bar{\varepsilon}\right)^{n} \dot{\varepsilon}^{m}
$$

In this chapter, in addition to M-K analysis, the Swift analysis [43] with Hill'93 yield criterion was used to predict the FLDs [62-63].

\section{Experimental work}

\subsection{Tensile test}

Tensile test specimens were cut according to ASTM E8 standard. At least two samples at each direction $\left(0^{\circ}, 45^{\circ}, 90^{\circ}\right)$ with respect to rolling directions were tested according to ASTM E517-00 
standard [64]. Tensile test was carried out under constant strain rate of $1 \times 10^{-3} \mathrm{~s}^{-1}$ at room temperature.

Although r-value is introduced as the ratio of width strain $\varepsilon_{w}$ to thickness strain $\varepsilon_{t}$, the thickness strain in thin sheets can not be accurately measured. Hence, by measuring longitudinal $\varepsilon_{l}$ and width strains and also by implementing the principle of volume constancy (Eq.20), the thickness strain was obtained as follows (Eq.21):

$$
\begin{aligned}
& \varepsilon_{l}+\varepsilon_{w}+\varepsilon_{t}=0 \\
& \varepsilon_{t}=-\left(\varepsilon_{l}+\varepsilon_{w}\right)
\end{aligned}
$$

The strain ratio (r-value) was calculated for all the materials at different direction $(0,45$ and $90^{\circ}$ to the rolling direction) (Eq.22). Subsequent to that, normal anisotropy $R$ (Eq.23) as well as planar anisotropy $\Delta R$ (Eq.24) were calculated according to ASTM E517-00 [64].

$$
\begin{gathered}
R_{x}=\frac{\varepsilon_{w, x}}{\varepsilon_{t, x}} \\
R=\frac{R_{0}+2 R_{45}+R_{90}}{4} \\
\Delta R=\frac{R_{0}+R_{90}-2 R_{45}}{2}
\end{gathered}
$$

Where: $x$ is the angle relative to the rolling direction $\left(0^{\circ}, 45^{\circ}, 90^{\circ}\right)$.

\subsection{Hydroforming bulge test}

The experimental apparatus used to conduct the hydraulic bulge test is composed of a tooling set, a hydraulic power generator and measurement devices. For the assembled toolset, maximum forming pressure can reach 500bars. To avoid any oil leakage during the forming process, a rubber diaphragm was placed between the conical part of the die and the conjunctive disc. A pressure gage and a dial indicator were used to measure the chamber pressure and bulge height, respectively during the bulging process. The indicator used in the experiments was delicate and could not withstand impact loads as the specimen bursts. Hence, for bulge testing of titanium sheets, at least three samples were burst in the absence of the indicator to discern the bursting pressures. Other samples were tested up to $90-95 \%$ of bursting pressure while the indicator was used to measure the bulge height during the process. In order to ensure pure stretching, the pre-fabricated draw bead was implemented at the flange area of the bulge 
samples. Consequently, pure stretching of the sheet material was obtained during the bulging process. Measuring devices were also calibrated before the test to ensure precise measurements. For bulge testing of sheet materials a die set was used. For bulge testing of Ti-6Al-4V, a large die set was designed and manufactured in order to reach the bursting pressure through available hydraulic pressure unit. Table 1 shows dimensions of the die set in addition to specifications of hydroforming bulge test apparatus. Hydroforming die used for bulge testing is shown in Fig.3.

\begin{tabular}{lc}
\hline & Die set specification \\
\hline Bulge diameter $\left(2 R_{d}\right)$ & $90 \mathrm{~mm}(3.54 \mathrm{in})$ \\
\hline Die fillet radius & $6 \mathrm{~mm}(0.236 \mathrm{in})$ \\
\hline Maximum chamber pressure & $50 \mathrm{MPa}(7400 \mathrm{psi})$ \\
\hline Flow rate & $2.5 \mathrm{lit} / \mathrm{min}$ \\
\hline
\end{tabular}

Table 1. Specifications of hydroforming bulge apparatus.

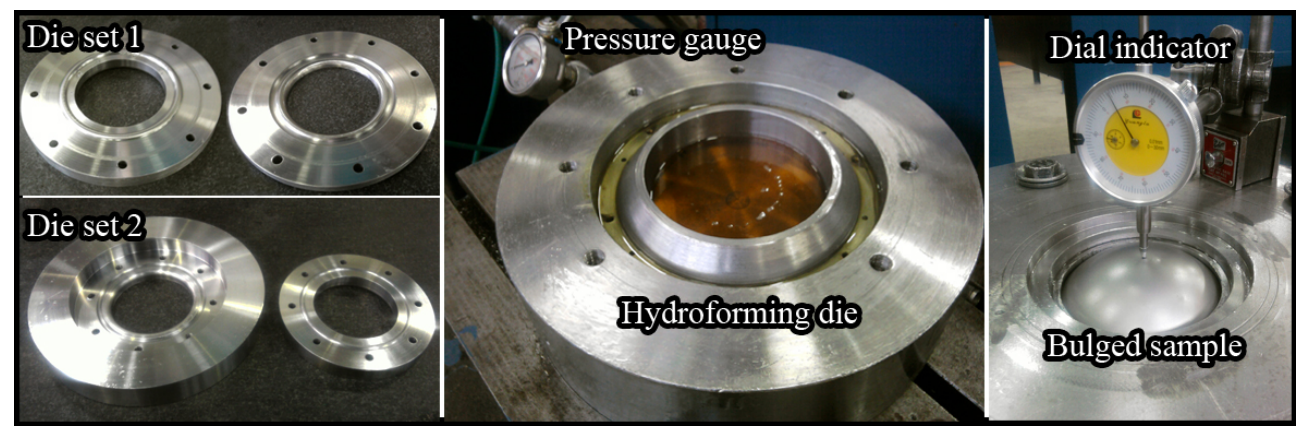

Figure 3. Hydroforming bulge test apparatus

\subsection{Forming limit diagrams}

In order to evaluate the FLDs, different strain paths, which cover full domain of the FLD, were examined and shown in Fig.4. These paths are spanned between the uniaxial tension region $\left(\varepsilon_{1}=-2 \varepsilon_{2}\right)$ and the equi-biaxial stretching $\left(\varepsilon_{1}=\varepsilon_{2}\right)$. The linear strain paths are described through the strain ratio (Eq.25) parameter representative of the strain state.

$$
\rho=\frac{d \varepsilon_{2}}{d \varepsilon_{1}}
$$




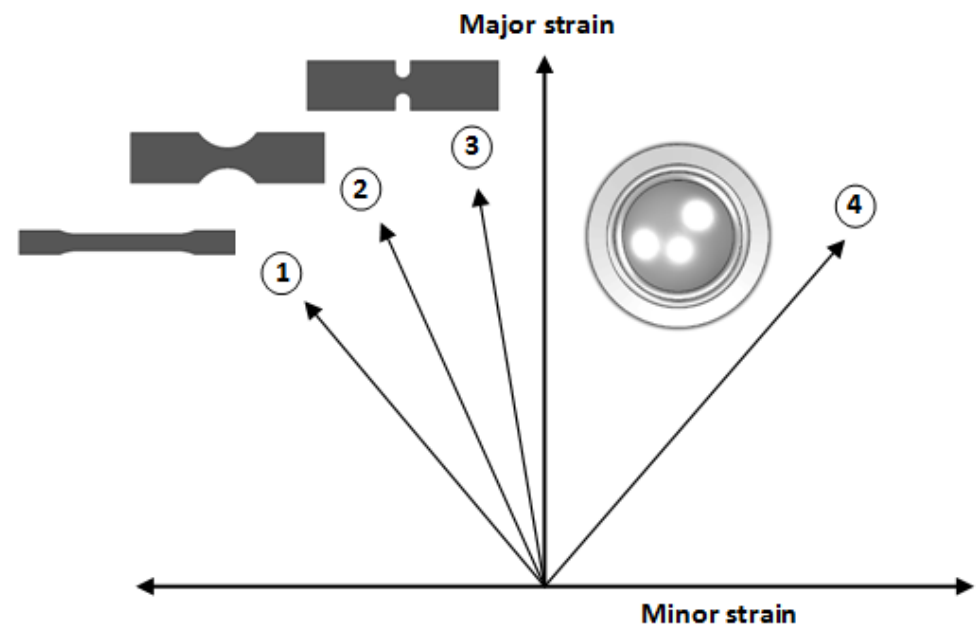

Figure 4. Different types of specimen representative of the linear strain paths

\subsection{Preparation of the specimens}

Three different shapes of tensile specimens were prepared using wire EDM. According to Fig. 4 , a non-grooved specimen was prepared to simulate the strain path\#1, two distinctive grooved specimens were used to obtain draw points representing the strain paths\#2 and 3. The nongrooved and grooved specimens were then drawn under a linear load. The specimens are shown in Figures 5-7 and the dimensions are listed in Table 2.

In order to obtain the tension-tension side of the FLD (pure stretching region), the bulge test specimens were prepared. The bulge samples for simulation of the strain path\#4, were $160 \mathrm{~mm}$ in diameter and the cavity diameter of circular dies was $90 \mathrm{~mm}$ (as shown in Table 1). LASER imprinting technique was used to print a grid of circles on the surface of the tension and the bulging samples. The circles were $2 \mathrm{~mm}$ in diameter. The diameter of the circles of the grids have been measured before and after the deformation throughout the major and minor principal directions taking as reference a perpendicular axis system placed in the geometric centre of each circle or in the centre of the tension specimen. These principal directions are parallel and perpendicular, respectively, to the rolling direction of the sheet.

Tensile specimens were tested up to the fracture point. Likewise, bulge testing of the bulge samples were carried out to reach the bursting point. Subsequent to that, diameters of ellipses which were the conclusions of deformed circles were measured precisely. 


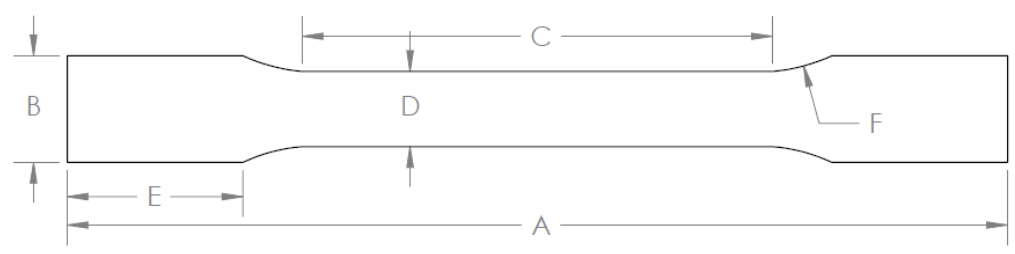

Figure 5. Uniaxial tensile specimen representative of strain path\#1 (no.1).

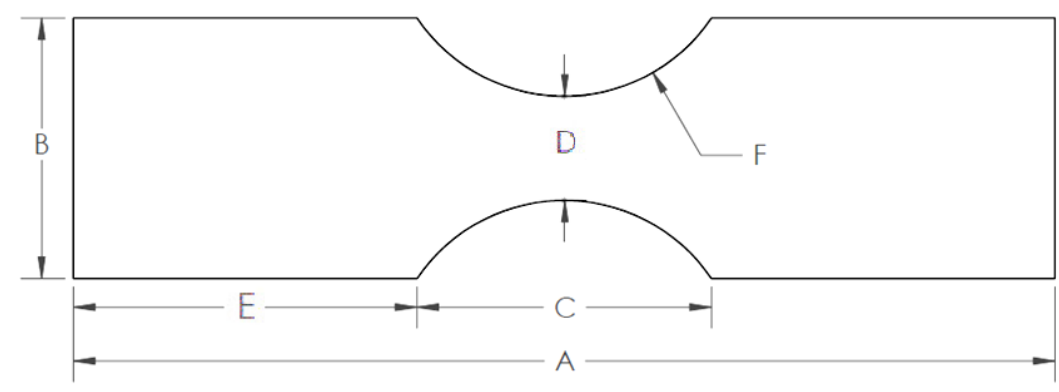

Figure 6. Grooved specimen representative of strain path\#2 (no.2).

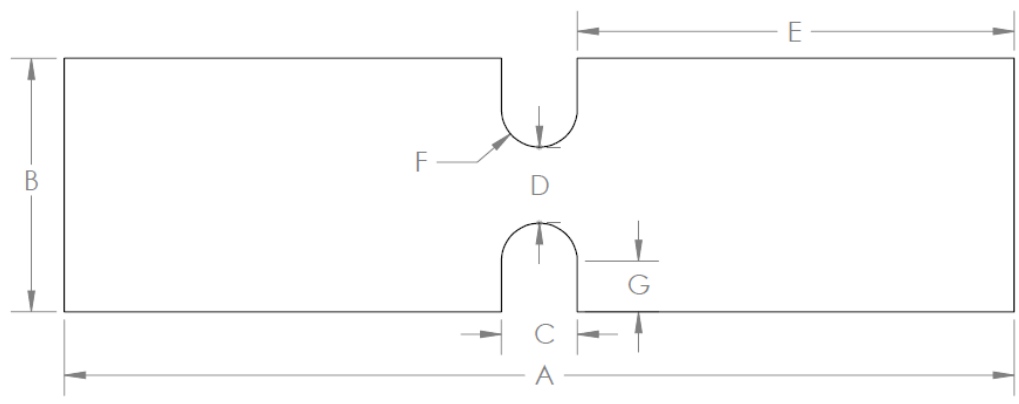

Figure 7. Grooved specimen representative of strain path\#3 (no.3).

\begin{tabular}{lcccccccc}
\hline Specimens no. & $\mathbf{A}(\mathbf{m m})$ & $\mathbf{B}(\mathbf{m m})$ & $\mathbf{C}(\mathbf{m m})$ & $\mathbf{D}(\mathbf{m m})$ & $\mathbf{E}(\mathbf{m m})$ & $\mathbf{F}(\mathbf{m m})$ & $\mathbf{G}(\mathbf{m m})$ \\
\hline 1 & 150 & 17 & 75 & 12 & 28 & $R 20$ & - \\
\hline 2 & 150 & 40 & 45 & 16 & 52.5 & $R 26$ & - \\
\hline 3 & 150 & 40 & 12 & 12 & 69 & $R 6$ & 8 \\
\hline
\end{tabular}

Table 2. Dimensions of the tensile specimens 


\section{Numerical approach}

More recently, several researchers [19, 65-67] have investigated the forming limit diagrams through finite element codes. In this chapter, Autoform Master 4.4 was employed for FE analysis of forming limit diagrams. The setting of the numerical simulation is based on the hemispherical punch and different shapes of specimens, as shown in Fig.8. Descriptions of the specimen dimensions and the geometrical model used in the simulation are shown in Table 3 and 4, respectively. The tensile properties of sheet metal were then input into the program and forming limit diagram were generated in Autoform 4.4 software using Keeler method [16]. Autoform 4.4 software automatically generates yield surface proposed by Banabic (BBC yield surface) and Hill for sheet materials when anisotropy coefficients and elasto-plastic behavior of sheet are imported. In Autoform the use of the shell element for the element formulation is mandatory, and therefore default, for the process steps Drawing, Forming, Bending and Hydroforming. Moreover, since for titanium and ultra high strength steels more complex material laws (for example Barlat or Banabic) are used, Autoform uses the implicit integration algorithm which contribution to the total calculation time is substantially smaller.

In this approach, CAD data were modeled in CATIA software first and then imported into Autoform 4.4 environment. In order to cover full range of the FLD, different specimens with different groove dimensions were modelled to simulate the tension-compression to tensiontension side of the FLD (Fig.8).

For the FE simulation, the punch, holder and die were considered as rigid parts. A displacement rate of $1 \mathrm{~mm} / \mathrm{s}$ was assumed for the hemispherical punch while for the clamping a draw bead with lock mode was selected to ensure pure stretching of the sheet into die cavity. Friction coefficient was taken to be 0.15 between the surfaces. The virtual samples were engraved with the gridded pattern of $3 \mathrm{~mm}$ diameter circles (Fig.8). Major and minor strains were recorded after each time step to evaluate the numerical FLD.

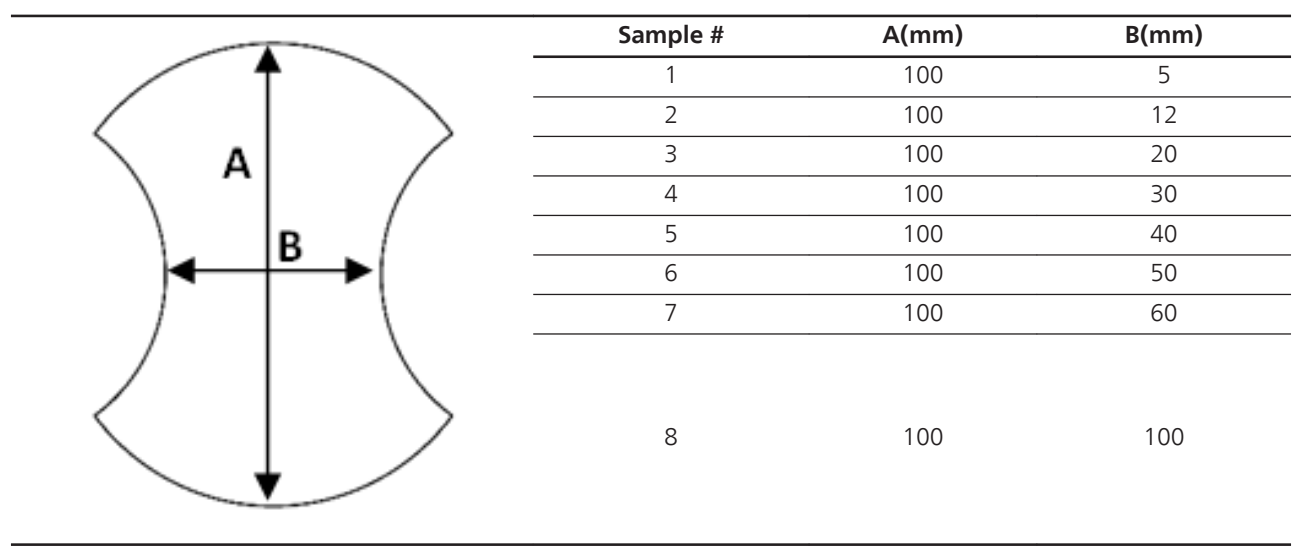

Table 3. Dimensions of different FLD samples prepared for FE approach 


\begin{tabular}{lc}
\hline Process parameter & Value/Type \\
\hline Punch diameter $(\mathrm{mm})$ & 50 \\
\hline Diameter of die opening $(\mathrm{mm})$ & 55 \\
\hline Die profile radius $(\mathrm{mm})$ & 8 \\
\hline Punch speed $(\mathrm{mm} / \mathrm{s})$ & 1 \\
\hline Punch travel & Up to rupture \\
\hline Clamping type & Draw bead (lock mode) \\
\hline
\end{tabular}

Table 4. Process parameters used for the simulation

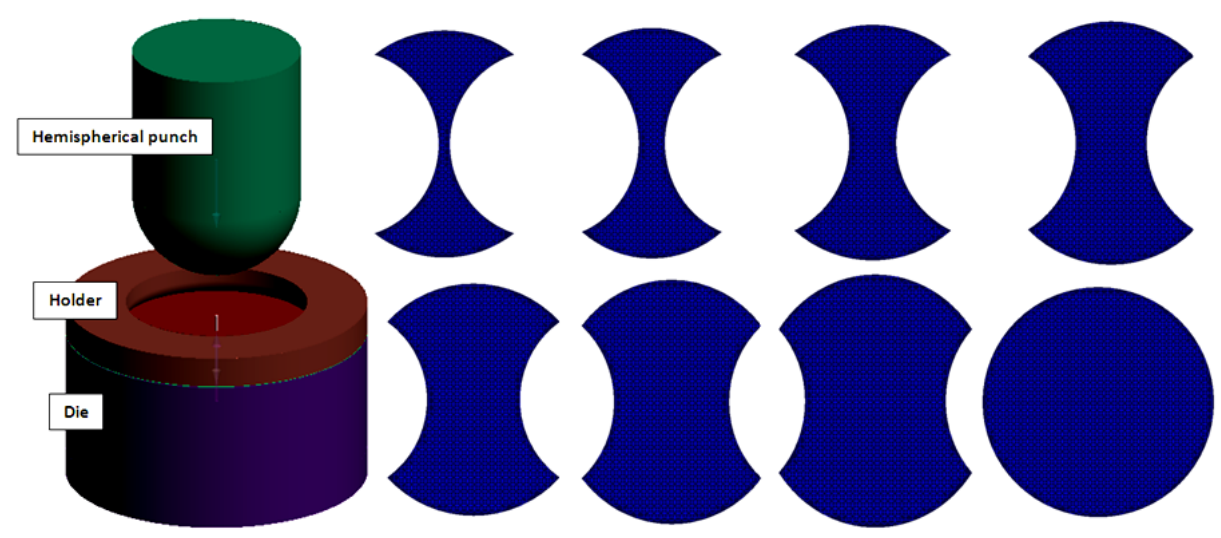

Figure 8. Schematic view of the model used in FE analysis as well as gridded sample shapes

\section{Results and discussion}

\subsection{Tensile test}

Table 5 illustrates mechanical properties of the tested sheet material deduced from the tensile test at room temperature. Tensile tests results on $1.08 \mathrm{~mm}$ thick Ti-6Al-4V sheets show the average values for strain-hardening (n) and anisotropy (r) are $(0.151,3.63)$. As it can be seen Ti alloy has large plastic strain ratio (r) values. Generally higher strain-hardening exponent (n) delays the onset of instability and this delay, enhances the limiting strain (i.e. a better stretchability and formability is achieved with higher (n) value). Also, increasing plastic strain ratio (r) results in a better resistance to thinning in the thickness direction during drawing which in turn increase the formability of sheet material. On the other hand, high planar anisotropy will bring about earring effect in sheet metal forming processes especially in deep drawing process [19]. 


\begin{tabular}{|c|c|c|c|}
\hline \multirow{2}{*}{ Property } & \multicolumn{3}{|c|}{ Ti-6Al-4V } \\
\hline & $0^{\circ}$ & $45^{\circ}$ & $90^{\circ}$ \\
\hline Yield stress, $\sigma_{\mathrm{y}}(\mathrm{MPa})$ & 544 & 558 & 571 \\
\hline Ultimate tensile stress, $\sigma_{\text {uts }}(\mathrm{MPa})$ & 632 & 607 & 629 \\
\hline Work-hardening exponent, $\mathrm{n}$ & 0.151 & 0.134 & 0.167 \\
\hline Hardening coefficient, K (MPa) & 975 & 912.5 & 1022 \\
\hline Total elongation, $\delta(\%)$ & 30.7 & 27.2 & 28.0 \\
\hline Anisotropy factor, $r$ & 2.4644 & 4.1218 & 3.8292 \\
\hline Normal anisotropy, $R_{\text {ave }}$ & & 3.6343 & \\
\hline Poisson's ratio, $u$ & & 0.342 & \\
\hline
\end{tabular}

Table 5. Mechanical properties of tested sheet material obtained in tensile test

\subsection{Hydroforming bulge test}

\section{Investigation of bursting pressure}

As discussed in section 3, in order to discern the bursting pressure of Ti-6Al-4V sheet material, at least three specimens were bulged up to bursting point and average bursting pressure for these alloys was obtained (Table 6). After obtaining burst pressure, test samples were bulged up to $90-95 \%$ bursting pressure while the bulge height was being monitored by the indicator. The resulted bulging pressure vs. dome height curves were then extrapolated up to burst pressure by using a third order polynomial approximation. Fig.9 shows bulge pressure versus dome height for the tested material. In this figure, experimentally measured curves along with the extrapolated regions are depicted. In Fig.10 tested samples are shown.

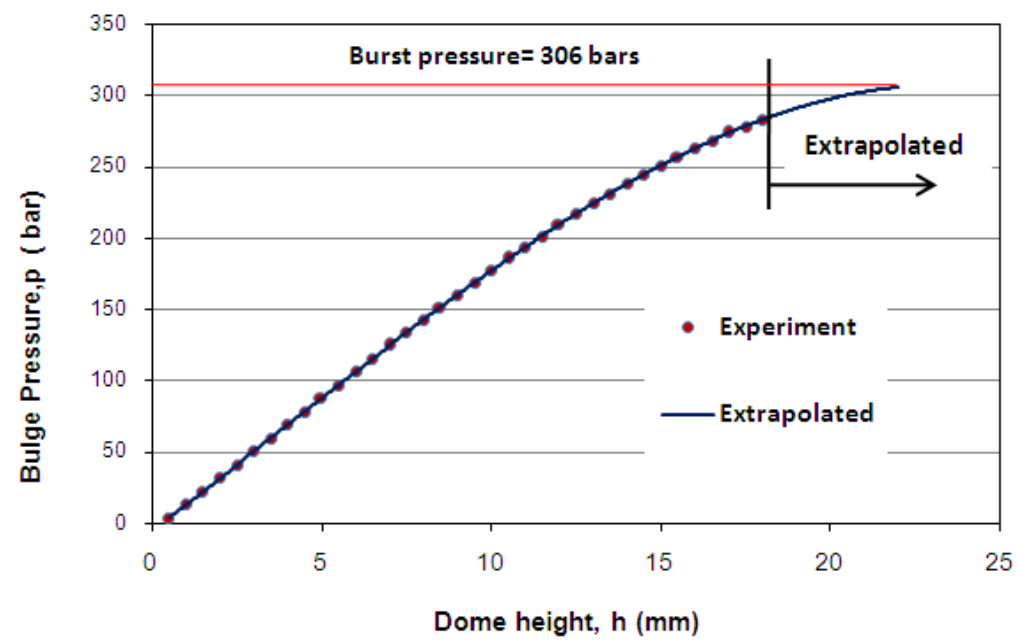

Figure 9. Experimental bulge pressure versus dome height curve for Ti-6Al-4V alloy (the curve is extrapolated) 


\begin{tabular}{ll}
\hline Burst pressure (Bars) & Ti-6Al-4V \\
\hline Sample 1 & 305 \\
\hline Sample 2 & 307 \\
\hline Sample 3 & 308 \\
\hline Sample 4 & 309 \\
\hline Average & 306 \\
\hline
\end{tabular}

Table 6. Burst pressure for different samples

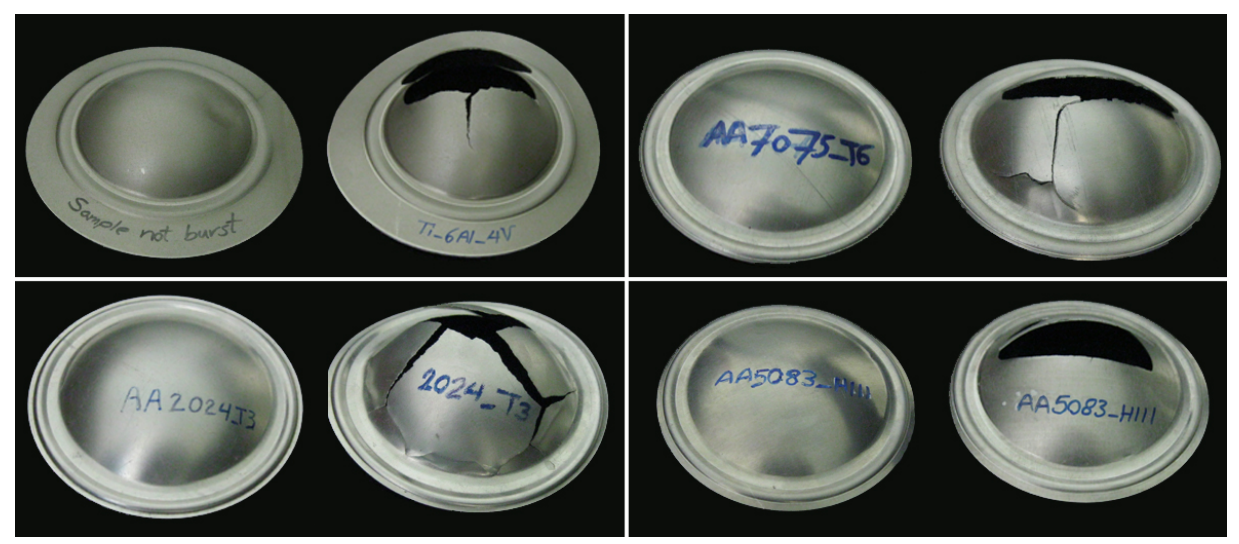

Figure 10. Burst and not burst samples of Ti-6Al-4V alloy

\section{Measurements/calculations of bulge radius}

In order to measure the bulge radius, several photographs of the bulged samples were taken. The camera was stabilized parallel to the blank. By using Solid Works software, 3-point circle was fitted to the bulge geometry and the radius of the bulge was measured. Fig.11 shows photographs of the bulged samples in stepwise approach. Measured and calculated bulge radii were compared. Among the compared approaches, Panknin's calculations for bulge radius yielded values closer to step-wise bulge results for the alloy tested. Fig.12 shows the comparison of calculated bulge radii with the step-wise measured bulge radius.

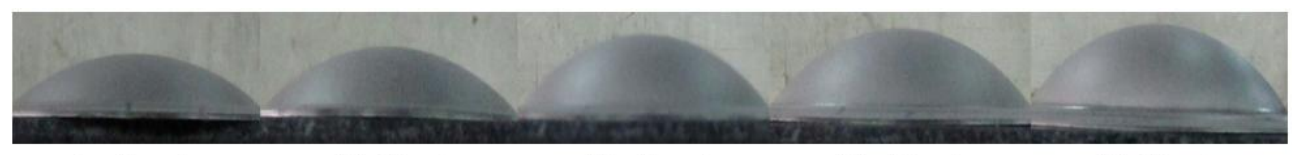
$\mathbf{h}_{1}, \mathbf{R}_{\mathrm{bl}}, \mathbf{t}_{\mathbf{l}}$
$\mathrm{H}_{2}, \mathrm{R}_{\mathrm{b} 2}, \mathrm{t}_{2}$
$\mathrm{H}_{3}, \mathrm{R}_{\mathrm{b} 3}, \mathrm{t}_{3}$
$\mathrm{H}_{4}, \mathrm{R}_{\mathrm{b} 4}, \mathrm{t}_{4}$
$\mathrm{H}_{5}, \mathrm{R}_{\mathrm{b} 5}, \mathrm{t}_{5}$

Figure 11. Photography of the bulged sample in stepwise approach 


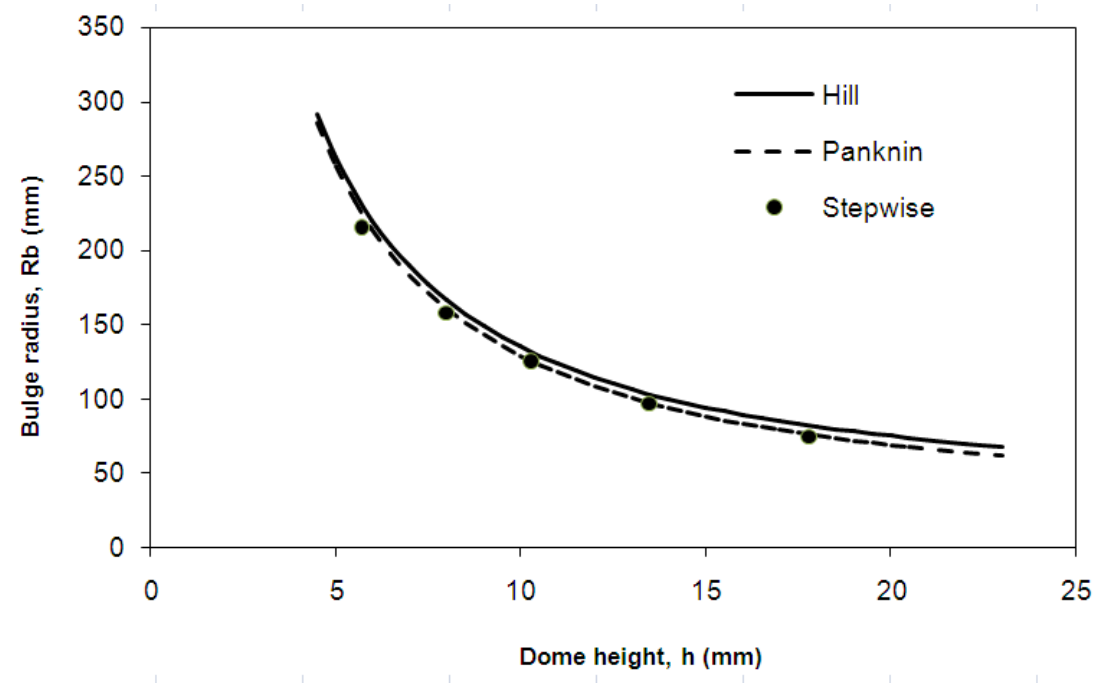

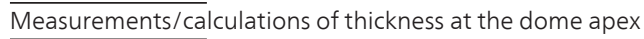

Figure 12. Comparison of calculated and measured bulge radii for Ti-6Al-4V

Eqs.3-5 were used to calculate the sheet thickness at the dome apex and the results were compared with the step-wise experiments. For measurement of the thickness at the dome apex, a $10 \mathrm{~mm}$ diameter circle was imprinted on the centre of each bulge sample. After each step, the major and minor diameters of the formed circle were measured by using an accurate caliper (0.05 mm accuracy). Subsequently, the effective strain was obtained for each step at the dome apex by replacing the instantaneous sheet thickness obtained from Eq.26 into Eq.7. The instantaneous thickness of the dome apex was extracted from Eq.8 and is shown as follows:

$$
t=\frac{t_{0}}{e^{\left(\varepsilon_{\theta}+\varepsilon_{\phi}\right)}}
$$

The results show that for calculating the sheet thickness at the dome apex, Kruglov's approach gives best results when compared with step-wise experiments. Fig.13 shows the comparison of calculated sheet thickness at the dome apex with the step-wise measured sheet thickness at the dome of the bulge.

As discussed before (Table 5) higher n-value indicates better stretchability and formability, therefore, for the same bulge height, sheet materials with larger n-values have lower thinning than sheet materials with smaller n-values. Also, when drawing is the deformation mode (e.g. tensile test) r-values strongly influence the thinning process of sheet deformation since higher $r$-values promote in-plane deformation $\left(\varepsilon_{1}>0, \varepsilon_{2}<0\right)$. As a result, Ti-6Al-4V sheet is very resistant to thinning due to the high normal anisotropy during 


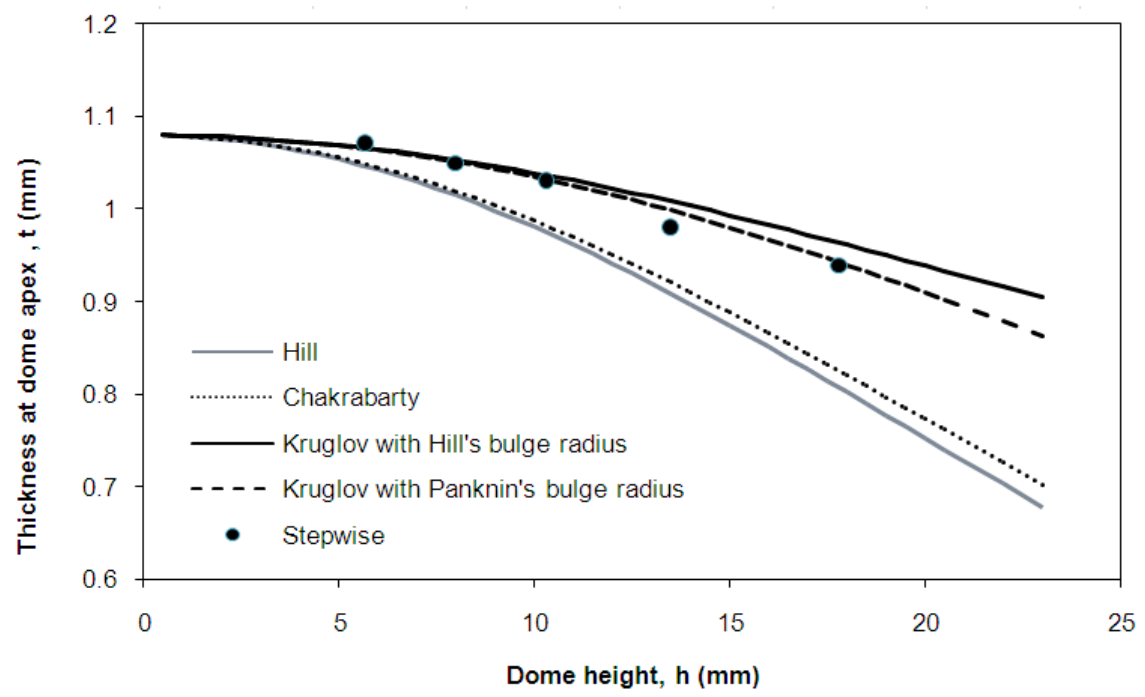

Influence of material properties and anisotropy on material deformation

Figure 13. Comparison of calculated and measured thickness at the dome apex for Ti-6Al-4V alloy

drawing deformations. On the other hand, when stretching is the deformation mode (e.g. bulge test), then both $\varepsilon_{1}$ and $\varepsilon_{2}$ are positive and thinning has to occur by constancy of volume (in this case the n-value having a strong influence). This experimental conclusion directly validates the numerical finding obtained by Gutscher et al. [2]. Their FE simulations indicated that anisotropy had very small influence on the correlation between the dome wall thickness at the apex of the dome and the dome height. They also concluded that anisotropy had no significant effect on the radius at the apex of the dome.

\section{Determination of flow stress curves}

Several flow stress curves were calculated for Ti-6Al-4V titanium sheet by using several proposed approaches discussed in previous sections. Calculated flow stress curves for titanium alloy were first corrected for anisotropy according to Eqs.9 and 10. Corrected curves are depicted in Fig.14. Step-wise measurements of stress-strain relationships in biaxial test are also shown in the same figure. As it can be seen, step-wise experiments are in good agreement with calculated flow stress curves when Kruglov's and Panknin's approaches are used for dome thickness and bulge radius calculations, respectively.

Fig.15 shows an overall comparison between flow stress curves obtained from tensile (up to instability point) and hydroforming bulge test. A constant scaling parameter was applied to transform biaxial stress-strain curve into effective flow stress curve which can be compared with the uniaxial curve [11]. Kruglov's sheet thickness calculation combined with Panknin's bulge radius calculation was used to obtain these curves. In this figure, tensile curves are depicted along the direction in which the highest elongation was obtained. This comparison 

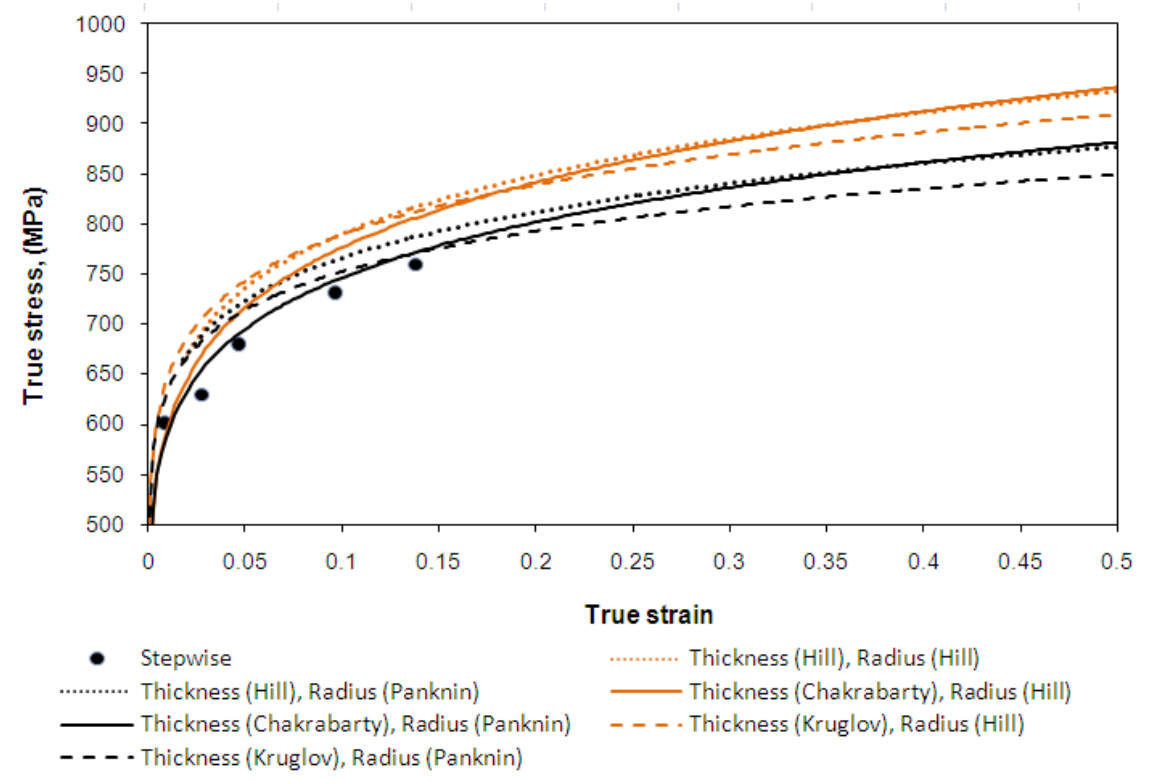

Figure 14. Comparison of measured and calculated flow stress curves for Ti-6Al-4V alloy

indicates, that balanced biaxial bulge test covers larger strain range than tensile test. Under balanced biaxial loading, the theoretical effective strain at instability is twice the instability strain under uniaxial loading. Comparing the data between uniaxial and bulge tests (Fig. 15 and Table 7), it can be seen that strain values obtained in the bulge test are higher than in the tensile test. This is an advantage of the bulge test, especially if the flow stress data is to be used for FE simulation, since no extrapolations is needed as in the case of tensile data. Moreover, in Table 7 it is shown that the percent difference is as high as $504 \%$ (for Ti-6Al-4V). This emphasizes the importance of the bulge test because of its capability to provide data for a wider range of strain compared to the traditional tensile test. Also, the constant scaling factor $\left(\mathrm{k}_{\mathrm{b}}\right)$ [11], which transforms biaxial stress-strain relationships into the effective stress-strain curves, is 0.937 for the tested material.

Ti-6Al-4V 


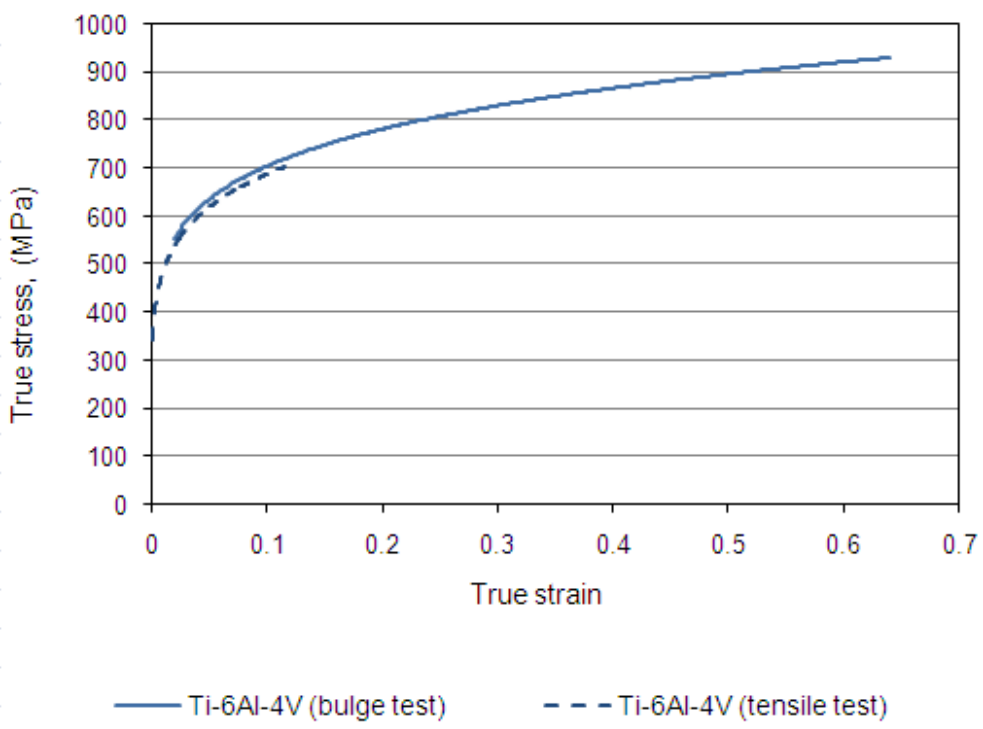

Figure 15. Comparison of effective flow stress curves obtained from tensile and bulge tests

\subsection{Determination of the FLD}

High resolution photography was employed to measure the diameters of the deformed circles imprinted on the samples (Fig.16). Non-deformed circles were used for calibration of the pictures. As a result, deformed circles were measured using measuring techniques in Solidworks software. Ellipses located in the fractured region, were considered as unsafe points. Likewise, ellipses with one row offset from the fractured region were considered as marginal points and ellipses located in other rows of imprinted grids were considered as safe points. Eqs.27 and 28, were used to obtain true major strain $\left(\varepsilon_{1}\right)$ and true minor strain $\left(\varepsilon_{2}\right)$ from the measured diameters considering the approach shown in Fig.17.

$$
\begin{aligned}
& \varepsilon_{1}^{*}=\operatorname{Ln} \frac{d_{1}}{d_{0}} \\
& \varepsilon_{2}^{*}=\operatorname{Ln} \frac{d_{2}}{d_{0}}
\end{aligned}
$$

\section{Experimental determination and theoretical calculation of the FLD}

One of the most important factors for prediction of FLD through the M-K analysis is the applied constitutive yield model. Fig.18 presents the experimental and numerical forming limits for Ti-6Al-4V titanium alloy. For numerical analysis, yield surfaces were described by Hill93 and 
BBC2000 yield functions and hardening model was expressed by Swift equation. As it can be observed in Fig.18, although curves predicted using Hill93-Swift model and M-K with BBC2000 are in rather good agreement with the experimental data, the best prediction is obtained when M-K model when the yield surface of Hill93 and initial geometrical defect $\left(f_{0}\right)$ of 0.955 , are used. As it can be observed in Fig.18, for Ti-6Al-4V sheet alloy, curve predicted using Hill-Swift model has small deviation from the experimental data from uni-axial region ( $\rho=-1 / 2$ ) to equi-biaxial region $(\rho=1)$. Moreover, slight difference in stretching region of the FLD between the experimental data points and the theoretical curve can be seen when BBC2000 is used as the yielding surface for the M-K model.

Note: As discussed by Graf and Hosford [29], applying prestrain in biaxial tension $(\rho=1)$ will decrease the formability if followed by plane strain or biaxial tension. Moreover, for uniaxial tension sample $(\rho=-1 / 2)$, if both prestrain and final testing with $\varepsilon_{1}$ are applied normal to the rolling direction, the FLD will be increased for subsequent plane strain and biaxial regions. Furthermore, for plane strain sample $(\rho=0)$ a slight increase of the overall level of the curve is expected when prestrain and final testing with $\varepsilon_{1}$ are applied normal to the rolling direction.

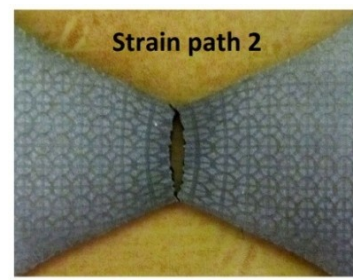

Strain path 1
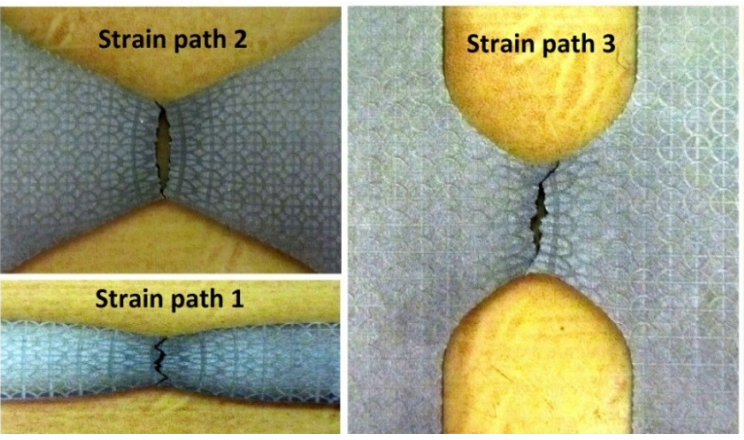

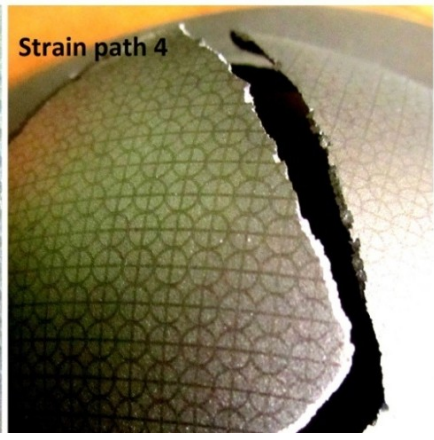

Figure 16. The ruptured tensile and bulge specimens

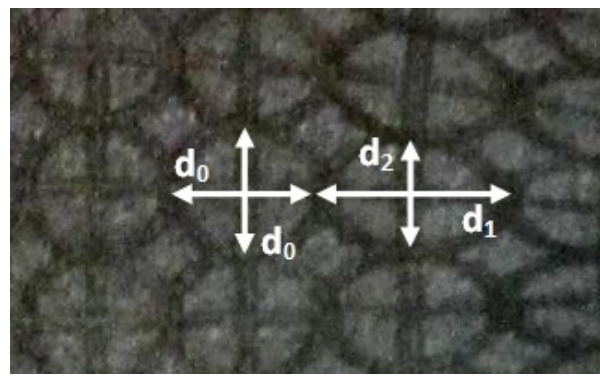

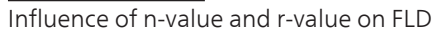

Figure 17. Deformation of the grid of circles to ellipses. 
Generally, there are two material properties which have significant influence on forming limit diagram; the anisotropy and the work-hardening exponent (n-value). R-values less than one $\left(\mathrm{r}_{\mathrm{ave}}<1\right)$, will result in the reduction of limit strains in drawing side of the FLD and lower levels for the FLD in plane strain region is expected. For $R$-values larger than one $\left(r_{a v e}>1\right)$, the opposite trend is expected

Consequently, among the tested sheets, Ti-6Al-4V severely resists to thinning during the sheet metal forming processes.

For most materials, forming limit curve intersects the major strain axis at the point equivalent to n-value. As n-value decreases, the limit strain level decreases. For Ti-6Al-4V, the major strain values are approximately 0.14 and 0.16 at plane strain region of the FLD.
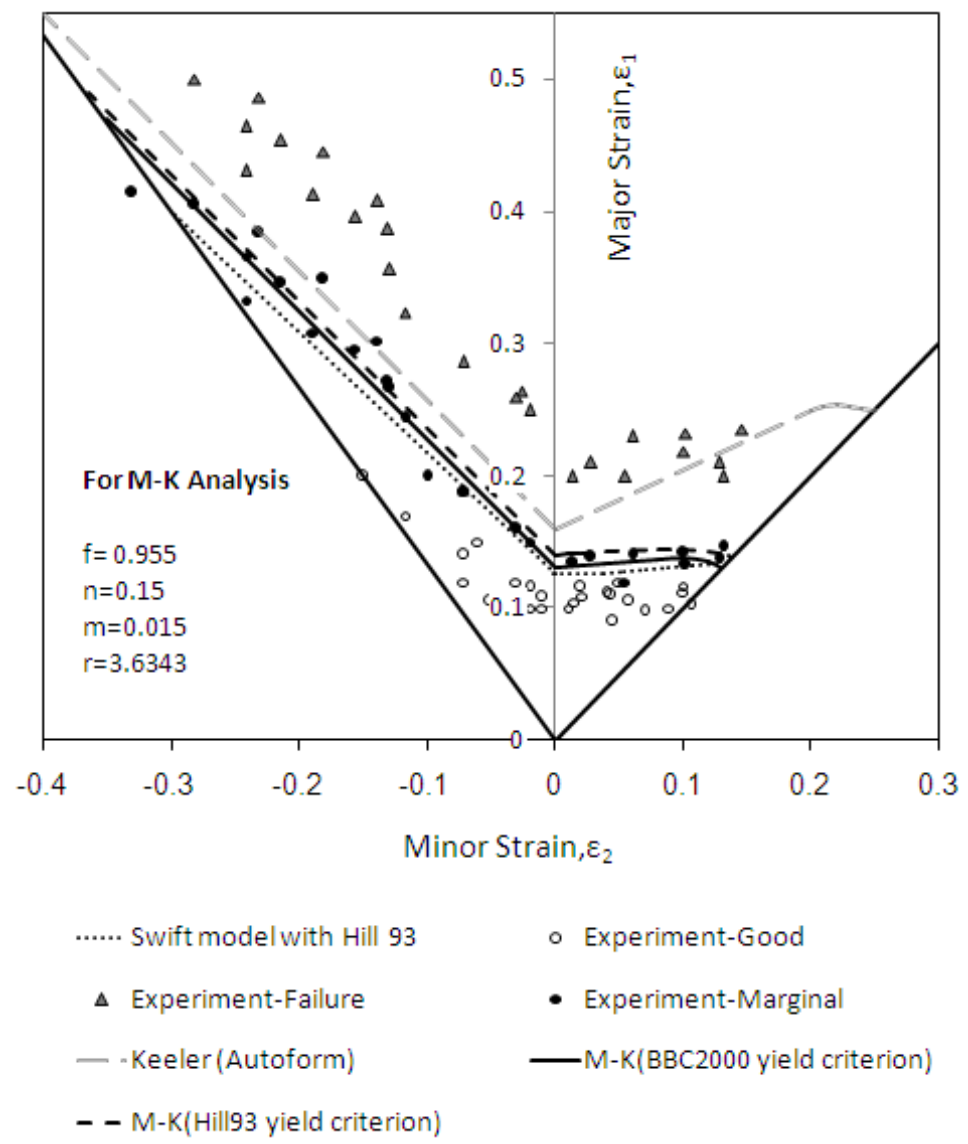

Comparison of experimental FLD with other works

Figure 18. Experimental and calculated forming limit diagram for Ti-6Al-4V alloy. 
Fig.19 compares the FLDs for $1.08 \mathrm{~mm}$ thick Ti-6Al-4V sheet determined in this study and the same sheet investigated by Djavanroodi and Derogar [19] during hydroforming deep drawing process. Frictional effect between the toolset and the sheet were not considered in their study. Moreover, in hydroforming deep drawing process, the strain rate is far different from the bulge and the tensile test method. Consequently, the experimental procedure and the strain rate are two reasons for this offset between the experimental FLD results for Ti-6Al-4V sheet.

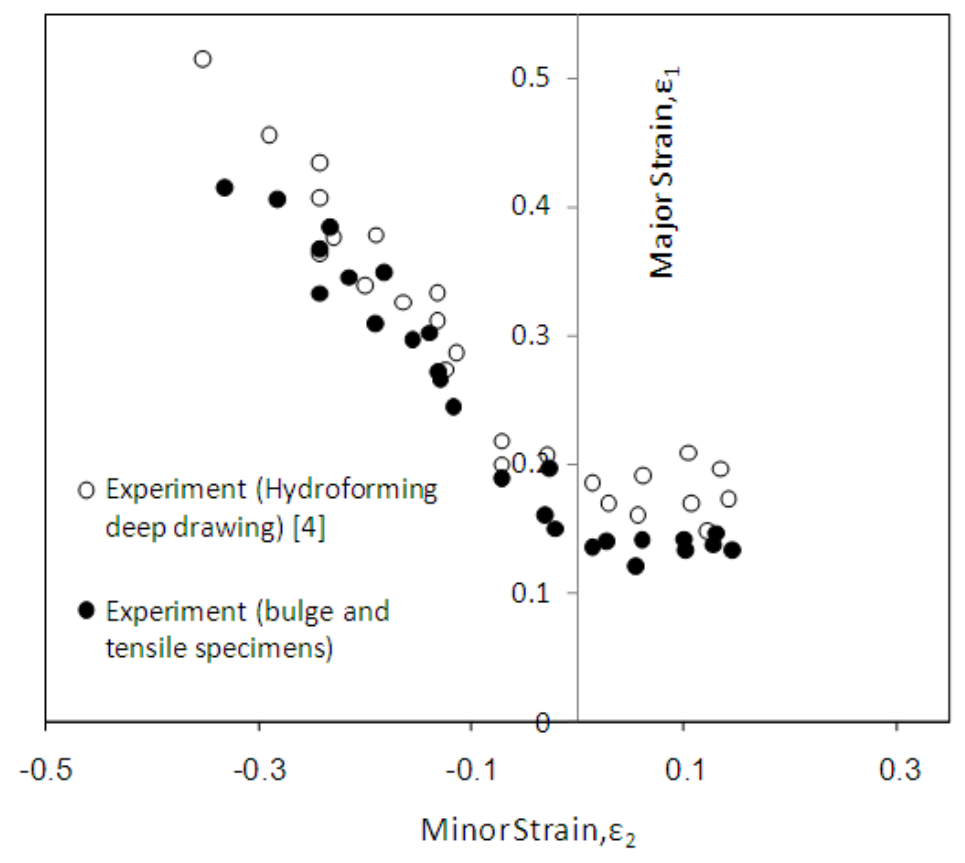

Figure 19. Comparison of forming limit diagrams for Ti-6Al-4V alloy.

\subsection{Finite element analysis}

Figs.20 and 21 show the numerical results generated by Autoform 4.4. The mechanical properties were input into the software, and the yield surface and FLD were generated as shown in Fig.20. Fig.21 shows that engraved circles were deformed and their shapes were changed to ellipses. The major and minor diameters of the ellipses were measured in the software to simulate the FLDs through the FE method. Fig.22 shows the comparison of the experimental and numerical FLDs. As shown in the figure, employing Hill's yield criterion for Ti sheet will result in better prediction of the FLDs compared to experimental data. Predicted FLDs using the industrial sheet metal forming code showed that the shape of the yield loci will have influence on the level of the FLD. Moreover, Fig.22 shows that necking points predicted by Hill's yield criterion and BBC yield criterion stand in good agreement compared to the 
experimental marginal points, the overall comparison shows a fair agreement between FE results and data obtained from the experiments. The small deviation between numerical and experimental results may be the conclusion of frictional effects between hemispherical punch (in FE simulation) and the sheet metals. While frictional effects remained as an unknown, in order to define the FLDs for different materials, either procedures without frictional effects should be employed or the effect of friction should be taken into account.
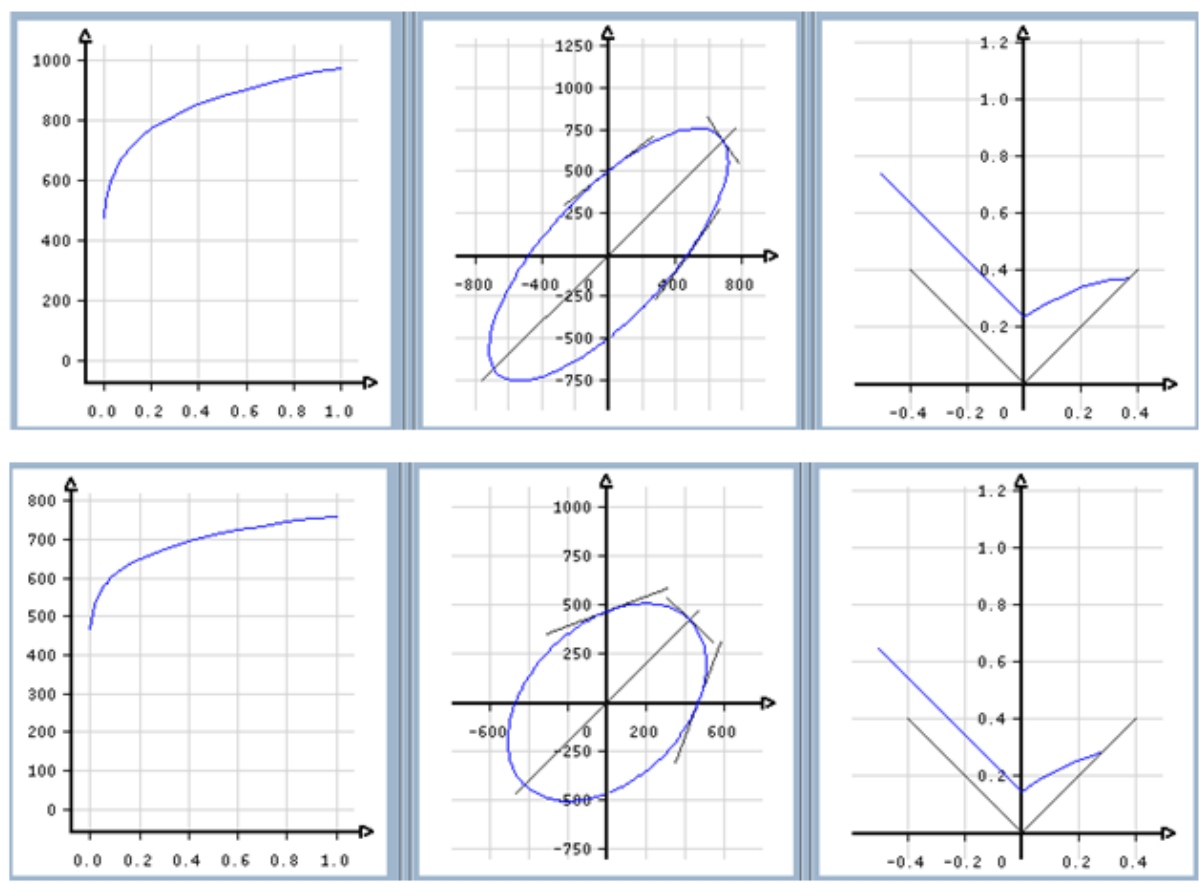

Figure 20. Numerical flow stress, yield locus and FLD generated in Autoform software. 


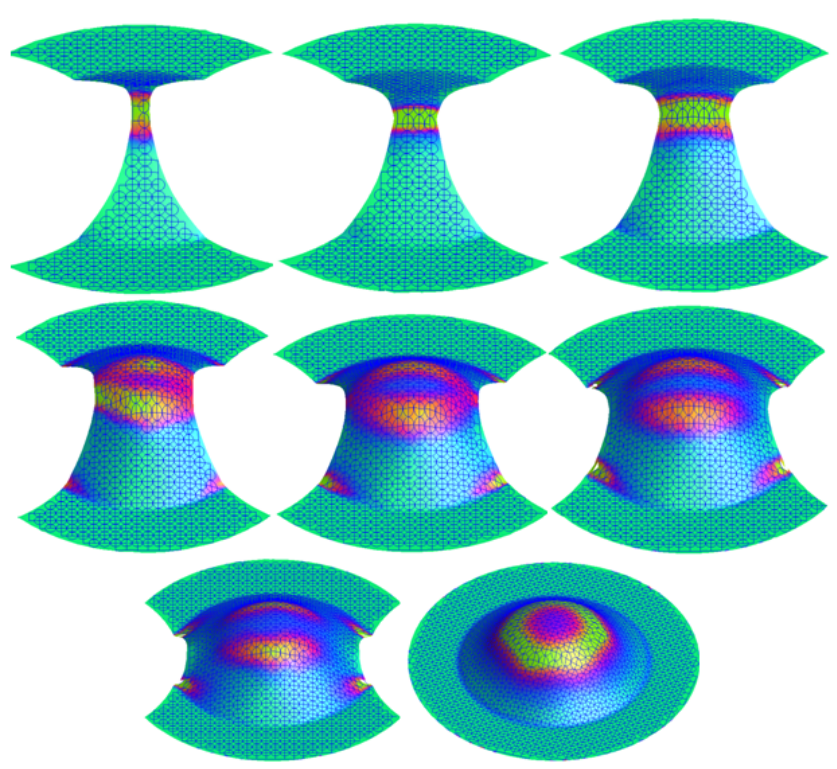

Figure 21. Deformed specimens simulated using Autoform software

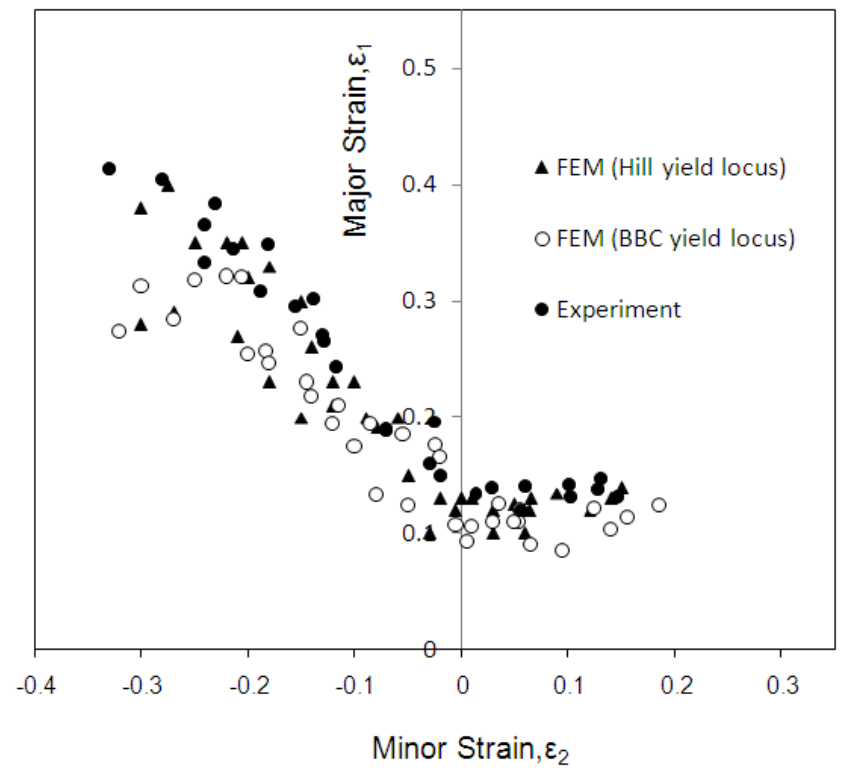

Figure 22. Comparison of the experimental FLD with the ones obtained by FEM for Ti-6AI-4V alloy 
Although the forming behavior of materials can be well expressed through uni-axial tensile tests, the theoretical prediction of FLD may still lie in large deviations from the experimentally determined FLDs. This finding proves that suitable theoretical approaches depend not only on the thorough understanding of the forming behavior of materials, but also on the suppositions for yield surfaces as well as material specifications.

\section{Conclusions}

Based upon the experimental, theoretical and numerical approaches used in this research the following conclusions could be drawn for forming titanium sheet alloys at room temperature:

1. Several approaches were used to generate true stress strain data based on thebulge test. Equations based on Kruglov and Panknin gave the most accurate results comparing to the step-wise experimental measurements.

2. Tensile tests showed that Ti-6Al-4V sheet alloy has large plastic strain ratio (r) values. Generally higher strain-hardening exponent (n) delays the onset of instability and this delay, enhances the limiting strain (i.e. better stretchability is achieved with higher nvalue).

3. Investigation of the influence of material anisotropy showed that increase in normal anisotropy would result in lower thickness thinning when drawing is the deformation mode and higher n-value would bring about higher bulge height, lower bulge radius and lower thickness thinning when stretching is the deformation mode.

4. The comparison between uniaxial and balanced biaxial bulge tests indicates that, in bulge test the flow stress curve can be determined up to larger strains than in the tensile test. This is an advantage of the bulge test, especially for metal forming processes in which the state of stress is almost biaxial; using bulge test is a more suitable method for obtaining the flow stress of the above sheet materials for use as an input to Finite Element (FE) simulation models.

5. It was shown that the percent difference for maximum plastic strain obtained from bulge and tensile test is as high as 504\% (for Ti-6Al-4V).

6. For Ti-6Al-4V alloy, the best agreement between experimental and theoretical approaches is achieved when the M-K with Hill'93 yield criteria is used. As a result, the overall comparison shows a well agreement between FE results and data obtained from the experiments.

7. The small deviation between numerical and experimental results may be the conclusion of frictional effects between hemispherical punch (in FE simulation) and the sheet metals. 


\section{Nomenclature}

\begin{tabular}{|c|c|}
\hline Nomenclature & Description \\
\hline$d_{d}$ & Die diameter \\
\hline$h_{b}$ & Bulge height \\
\hline$n$ & Work hardening exponent \\
\hline$p$ & Bulge pressure \\
\hline$t_{0, t}$ & Initial thickness, instantaneous thickness \\
\hline$c, p, q$ & Coefficients of Hill'93 yield criterion \\
\hline$a, b, c, k$ & Material parameters in BBC2000 criterion \\
\hline$d, e, f, g$ & Anisotropy coefficients of material in BBC2000 yield criterion \\
\hline$m$ & Strain rate sensitivity factor \\
\hline$t^{a}{ }_{0}, t^{b}{ }_{0}$ & Initial thicknesses at homogeneous and grooved region \\
\hline$f_{0}$ & Geometrical defect \\
\hline$R_{0}, R_{45}, R_{90}$ & Anisotropy coefficients \\
\hline K & Strength coefficient \\
\hline$R$ & Average normal anisotropy \\
\hline$R_{b}$ & Bulge radius \\
\hline$R_{d}$ & Die radius \\
\hline$R_{f}$ & Upper die fillet radius \\
\hline$\Delta R$ & Planar anisotropy \\
\hline $\bar{\sigma}_{\text {isotropic }}$ & Isotropic effective stress \\
\hline $\bar{\sigma}_{\text {anisotropic }}$ & Anisotropic effective stress \\
\hline $\bar{\sigma}$ & Effective stress \\
\hline$\sigma_{1}, \sigma_{2}$ & Principle stresses \\
\hline$\sigma_{0}, \sigma_{90}$ & Yielding stresses obtained from tensile tests \\
\hline$\sigma_{b}$ & Biaxial yield stress \\
\hline$\varepsilon_{\theta}, \varepsilon_{\phi^{\prime}} \varepsilon_{t}$ & Principal strains \\
\hline$\varepsilon_{1}, \varepsilon_{2}$ & Major and minor limit strain \\
\hline$\dot{\varepsilon}$ & Effective strain \\
\hline$\varepsilon_{0}$ & Pre-strain \\
\hline$\dot{\varepsilon}$ & Strain rate \\
\hline$d \varepsilon_{2 a} d \varepsilon_{2 b}$ & Strains parallel to the notch \\
\hline
\end{tabular}




$$
\begin{aligned}
& \dot{\varepsilon}_{\text {isotropic }} \\
& \dot{\varepsilon}_{\text {anisotropic }} \\
& \varepsilon_{l,} \varepsilon_{w} \\
& \Gamma, \psi \\
& \rho
\end{aligned}
$$

Isotropic effective strain

Anisotropic effective strain

Longitudinal strain, Width strain

Functions of the second and third invariants

Strain ratio

\section{Author details}

F. Djavanroodi ${ }^{1}$ and M. Janbakhsh ${ }^{2 *}$

*Address all correspondence to: roodi@qec.edu.sa; miladjanbakhsh@mecheng.iust.ac.ir

1 Mechanical Engineering Department, College of Engineering, Qassim University, Saudi Arabia

2 School of Mechanical Engineering, Iran University of Science and Technology, Saudi Arabia

\section{References}

[1] Koç M., Billur E., Cora O. N. An experimental study on the comparative assessment of hydraulic bulge test analysis methods. Journal of Materials \& Design 2011; 32: 272-281.

[2] Gutscher G., Chih H., Ngaile G., Altan T. Determination of flow stress for sheet metal forming using the viscous pressure bulge (VPB) test. Journal of Materials Processing Technology 2004;146: 1-7.

[3] Nasser A., Yadav A., Pathak P., Altan T. Determination of the flow stress of five AHSS sheet materials (DP 600, DP 780, DP 780-CR, DP 780-HY and TRIP 780) using the uniaxial tensile and viscous pressure bulge (VBP) tests. Journal of Materials Processing Technology 2010; 210: 429-436.

[4] Mahabunphachai S., Koç M. Investigations on forming of aluminum5052 and6061 sheet alloys at warm temperatures. Journal of Materials \& Design 2010;31: 2422-2434.

[5] Smith L. M., Wanintrudar C., Yang W., Jiang S. A new experimental approach for obtaining diffuse-strain flow stress curves. Journal of Materials Processing Technology 2009; 209: 3830-3839.

[6] Hill R. A theory of plastic bulging of a metal diaphragm by lateral pressure. Philosophical Magazine 1950; 41(322): 1133-1142. 
[7] Dziallach S., Bleck W., Blumbach M., Hallfeldt T. Sheet metal testing and flow curve determination under multiaxial conditions. Advanced Engineering Materials 2007; 9(11): 987-994.

[8] Iguchi T., Yanagimoto J. Measurement of ductile forming limit in non-linear strain paths and anisotropic yield conditions for $11 \% \mathrm{Cr}$ steel sheets. Iron Steel Inst Jpn International 2007;47(1): 122-130.

[9] Koh CW. Design of a hydraulic bulge test apparatus. MS Thesis. naval architecture and marine engineering; Massachusetts Institute of Technology: 2008

[10] Montay G., François M., Tourneix M., Guelorget B., Vial-Edwards C., Lira I. Strain and strain rate measurement during the bulge test by electronic speckle pattern interferometry. Journal of Materials Processing Technology 2007; 184: 428-35.

[11] Sigvant M., Mattiasson K., Vegter H., Thilderkvist P. A viscous pressure bulge test for the determination of a plastic hardening curve and equibiaxial material data. International Journal of Material Forming 2009; 2: 235-242.

[12] Banabic D., Vulcan M., Siegert K. Bulge testing under constant and variable strain rates of superplastic aluminium alloys. CIRP Annals Manufacturing Technology 2005; 1: 205-208.

[13] Altan T., Palaniswamy H., Bortot P., Mirtsch M., Heidl W., Bechtold A. Determination of sheet material properties using biaxial tests. In Proceedings of the 2nd international conference on accuracy in forming technology; Chemnitz, Germany; 2006

[14] Chamekh A., BelHadjSalah H., Hambli R., Gahbiche A. Inverse identification using the bulge test and artificial neural networks. Journal of Materials Processing Technology 2006; 177: 307-310.

[15] Rees D.W. Plastic flow in the elliptical bulge test. International Journal of Mechanical Sciences 1995; 37(4): 373-389.

[16] Keeler SP. Determination of forming limits in automotive stampings. SAE Technical Paper 1965;42: 683-691.

[17] Goodwin GM. Application of strain analysis to sheet metal forming problems in the press shop. SAE Technical Paper 1968; 60: 764-774.

[18] Janbakhsh M., Djavanroodi F., Riahi M. A comparative study on determination of forming limit diagrams for industrial aluminium sheet alloys considering combined effect of strain path, anisotropy and yield locus. Journal of Strain Analysis for Engineering Design 2012: 47(6): 350-361.

[19] Djavanroodi F, Derogar A. Experimental and numerical evaluation of forming limit diagram for Ti6A14V titanium and Al6061-T6 aluminum alloys sheets. Journal of Materials \& Design 2010;3: 4866-4875. 
[20] Rezaee-Bazzaz A., Noori H., Mahmudi R. Calculation of forming limit diagrams using Hill's 1993 yield criterion. International Journal of Mechanical Sciences 2011; 53(4): 262-270.

[21] Verleysen P., Peirs J., Van Slycken J., Faes K., Duchene L. Effect of strain rate on the forming behaviour of sheet metals. Journal of Materials Processing Technology 2011; 211(8): 1457-1564.

[22] Khan A.S., Baig M. Anisotropic responses, constitutive modeling and the effects of strain rate and temperature on the formability of an aluminum alloy. International Journal of Plasticity 2011; 27(4): 522-538.

[23] Palumbo G., Sorgente D., Tricarico L. A numerical and experimental investigation of AZ31 formability at elevated temperatures using a constant strain rate test. Journal of Materials \& Design 2010; 31: 1308-1316.

[24] Huang G.S., Zhang H., Gao X.Y, Song B., Zhang L. Forming limit of textured AZ31B magnesium alloy sheet at different temperatures. Transactions of Nonferrous Metals Society of China 2011; 21(4): 836-843.

[25] Inal K.,Neale K.W., Aboutajeddine A. Forming limit comparisons for FCC and BCC sheets. International Journal of Plasticity; 2005; 21(6): 1255-1266.

[26] Shu J., Bi H., Li X., Xu Z., Effect of Ti addition on forming limit diagrams of Nb-bearing ferritic stainless steel. Journal of Materials Processing Technology; 2012; 212(1): 59-65.

[27] Raghavan K.S., Garrison Jr W.M. An investigation of the relative effects of thickness and strength on the formability of steel sheet. Journal of Materials Science Engineering: A; 2010; 527(21-22): 5565-5574.

[28] Uppaluri R., Reddy N.V., P.M. Dixit P.M. An analytical approach for the prediction of forming limit curves subjected to combined strain paths. International Journal of Mechanical Sciences; 2011; 53(5): 365-373.

[29] Graf A, Hosford W. The influence of strain-path changes on forming limit diagrams of Al 6111 T4, International Journal of Mechanical Sciences 1994;36: 897-910.

[30] Tajally M, Emadoddin E. Mechanical and anisotropic behaviors of 7075 aluminum alloy sheets. Journal of Materials \& Design 2011; 32(3): 1594-1599.

[31] Hecker SS. Simple technique for determining forming limit curves. SAE Technical Paper 1975;5: 671-676.

[32] Tadros AK, Mellor PB. An experimental study of the in-plane stretching of sheet metal. International Journal of Mechanical Sciences 1978;20: 121-134.

[33] Gronostajski J, Dolny A. Determination of forming limit curves by means of Marciniak punch. IDDRG congress 1980;4: 570-578. 
[34] Raghavan KS. A simple technique to generate in-plane forming limit curves and selected applications. Metal Transaction A 1995;26: 2075-2084.

[35] Olsen, T.Y. Machines for ductility testing. Proc American Society of Materials 1920; 20: 398-403.

[36] Keeler, S.P. Plastic instability and fracture in sheet stretched over rigid punches. Phd Thesis, Massachusetts Institute of Technology, Boston, MA: 1961.

[37] Marciniak, Z., Limits of sheet metal formability. (in Polish) Warsaw, WNT, 1971.

[38] Nakazima, K., Kikuma, T., Hasuka, K., Study on the formability of steel sheets. Metallurgical Transaction 1975; 284: 678-680.

[39] Hasek, V. On the strain and stress states in drawing of large unregular sheet metal components (in German). Berichte aus dem Institute fiir Umformtechnik, Universitdit Stuttfart, 1973.

[40] Hoferlin E., Bael A.V., Houtte P.V., Steyaert G., nd Maré C.D. The design of a biaxial tensile test and its use for the validation of crystallographic yield loci, Modelling Simulation, Materials Science Engineering 2000;8: 423.

[41] Koh C.W. Design of a hydraulic bulge test apparatus, M.Sc thesis. Massachusetts Institute of Technology; 2008

[42] Hill R. A theory of yielding and plastic flow of anisotropic metals. Proceeding of Royal Society of London 1948;193A: 197-281.

[43] Swift HW. Plastic instability under plane stress. Journal of Mechanical Physics and Solids 1952;1: 1-18.

[44] Xu S, Weinmann K.L. Prediction of forming limit curves of sheet metal using Hill's 1993 user-friendly yield criterion of anisotropic materials, International Journal of Mechanical Sciences 1998;40: 913-925.

[45] Marciniak Z, Kuczynski K. Limit strains in the processes of stretched-forming sheet metal. International Journal of Mechanical Sciences 1967;9: 609-620.

[46] Marciniak Z, Kuczynski K, Pokora T. Influence of the plastic properties of a material on the forming limit diagram for sheet metal in tension. International Journal of $\mathrm{Me}$ chanical Sciences 1973;15: 789-805.

[47] Parmar A, Mellor P.B. Predictions of limit strains in sheet metal using a more general yield criterion, Int International Journal of Mechanical Sciences 1978;20: 385-391.

[48] Lei L, Kim J. Bursting failure prediction in tube hydroforming processes by using rigid-plastic FEM combined with ductile fracture criterion. International Journal of Mechanical Sciences 2002;44: 1411-1428. 
[49] Takuda H, Mori K. Prediction of forming limit in deep drawing of Fe/Al laminated composite sheets using ductile fracture. Journal of Materials Processing Technology 1996;60: 291-296.

[50] Takuda H, Mori K. Prediction Prediction of forming limit in bore-expanding of sheet metals using ductile fracture criterion. Journal of Materials Processing Technology 1999;92-93: 433-438.

[51] Takuda H, Mori K. Prediction Finite element analysis of limit strains in biaxial stretching of sheet metals allowing for ductile fracture. International Journal of Machine Tools \& Manufacture 2000;42: 785-798.

[52] Fahrettin O, Daeyong Li. Analysis of forming limits using ductile fracture criteria. Journal of Materials Processing Technology 2004;147: 397-404.

[53] Kumar S, Date P.P, Narasimhan K. A new criterion to predict necking failure under biaxial stretching. Journal of Materials Processing Technology 1994;45: 583-588.

[54] J.D. Bressan, J.A. Williams. The use of a shear instability criterion to predict local necking in sheet metal deformation, International Journal of Mechanical Sciences 1983;25: 155-168.

[55] Hill R. A user-friendly theory of orthotropic plasticity in sheet metals. International Journal of Mechanical Sciences 1993;35(1): 19-25.

[56] Banabic D., Kuwabara T., Balan T., Comsa D.S. An anisotropic yield criterion for sheet metals Journal of Materials Processing Technology 2004; 157-158: 462-465.

[57] Panknin W. The Hydraulic Bulge Test and the Determination of the Flow Stress Curves. Phd thesis, Institute for Metal Forming Technology, University of Stuttgart, Germany, 1959

[58] Chakrabarty J., Alexander J.M. Hydrostatic bulging of circular diaphragms. Journal of Strain Analysis 1970; 5: 155-161.

[59] Kruglov A.A., Enikeev F.U., Lutfullin RYa. Superplastic forming of a spherical shell out a welded envelope. Materials Science Engineering A 2002; 323: 416-426.

[60] Koç M., Aueulan Y., Altan T. On the characteristics of tubular materials for hydroforming - experimentation and analysis. International Journal of Machine Tools and Manufacture 2001; 41(5): 761-772.

[61] Butuc M.C. Forming limit diagrams. Definition of plastic instability criteria, Ph.D thesis, University do Porto; 2004.

[62] Banabic D. Limit strains in the sheet metals by using the new Hill's yield criterion (1993). Journal of Materials Processing Technology 1999;92-93: 429-432. 
[63] Wang L., Lee T.C. The effect of yield criteria on the forming limit curve prediction and the deep drawing process simulation, International Journal of Machine Tools \& Manuf.; 2006; 46: 988-995.

[64] ASTM Committee E28/Subcommittee E28.02, Standard Test Method for Plastic Strain Ratio $r$ for Sheet Metal, ASTM E517-00; 2006

[65] Bhagat, A. N. , Singh, Avtar, Gope, N. and Venugopalan T. Development of ColdRolled High- Strength Formable Steel for Automotive Applications. Materials and Manufacturing Processes, 2010;25(1): 202-205.

[66] Panda Sushanta Kumar, Kumar Ravi D. Experimental and numerical studies on the forming behavior of tailor welded steel sheets in biaxial stretch forming. Journal of Materials \& Design 2010;31: 1365-1383.

[67] Ko D.C, Cha S.H, Lee S.K, Lee C.J, Kim B.M. Application of a feasible formability diagram for the effective design in stamping processes of automotive panels. Journal of Materials \& Design 2010;31: 1262-1275. 
